agents, its inspectors of proposed risks and its medical examiners a sum of money equal in the aggregate to about 75 per cent. of the tabulated amount of all its first-year premiums. Moreover, while the companies may arbitrarily pay less than the amount named for the items mentioned, they can not pay more, and in fixing the amounts apportioned to agents, inspectors and examiners, respectively, they are bound by no law. It is unquestionably true, as shown above, that the medical fee bears no relation whatever either to the premium or to the face of the policy, but that the total amount paid to examiners is charged to a general expense fund.

The service required is, and very properly should be, equally thorough and uniform in all cases irrespective of the amount of the application. An examination made by any physician worthy of the trust and confidence placed in him by the company he represents will be just as complete and dependable in $\$ 1,000$ cases as in cases of any other larger amounts.

I maintain that every feature of the entire subject warrants a uniform fee for a uniform service, the one commen. surate with the other. If a uniform fee of $\$ 5$ would amount in the aggregate to a sum out of proportion to the aggregate amount of premiums received, then it should be placed at a lower figure, provided always that it should be uniform just so long as the service is uniform.

In cases where large amounts are applied for, the interest of the company would be better subserved by having the opinion of two examiners, paying each the original uniform fee, instead of paying one physician $\$ 7.50$ or $\$ 10$ for the same service and the identical opinion which, in smaller cases, would be rendered for a smaller fee.

In other instances where additional urinalyses are required, or a microscopic analysis of the urine or sputum is desired, reasonable extra compensation should be allowed.

In the foregoing remarks it has not been my intention to say or imply that the aggregate amount paid by companies having a graded fee bill is less than it should be, but it has been $m y$ purpose to criticise any sort of a graded medical fee bill as being a wholly unequitable method of distributing this compensation.

Having clearly shown, it seems to me, that all the essential conditions connected with the subject warrant a uniform fee for a uniform service, let us see if a uniform medical fee of $\$ 5$ is excessive. We have shown that the new legislation will allow the companies in securing new business to pay to their agents, inspectors and examiners a sum of money equal in the aggregate to about 75 per cent. of the aggregate amount of the first annual premiums.

Policies vary in amount from $\$ 1,000$ to $\$ 1,000,000$, but the amount of the average policy is not less than $\$ 2.000$, being at the end of the year 1905 for the Equitable $\$ 2,605$, for the Mutual Benefit, $\$ 2,301$; for the Mutual Iife, $\$ 2,306$; for the Massachusetts Mutual, $\$ 2,241$; for the Manhattan, $\$ 2,144$; for the Penn Mutual, $\$ 2,354$, and for the Provident Savings, $\$ 2,230$; but for illustration we will place the amount of the average policy at only $\$ 2,000$. The average premium for each $\$ 1,000$ of insurance on the standard forms of policies provided for in the new legislation is not less than $\$ 30$. Now, then, we have found that the average premium on the average policy is not less than $\$ 60$. We have shown that the "loading and mortality gains" equal about 75 per cent. of the premium, which on the average policy is $\$ 45$. On each (average) policy written the company will have not less than $\$ 45$ to be paid to the agent, the inspector and the examiner.

Now, deduct $\$ 1$ for the inspector, $\$ 5$ for the examiner and $\$ 1$ to help create a fund to pay the inspector and examiner in cases of rejected applications. The net result will be $\$ 38$ for the agent's commission, which is equal to more than 60 per cent. of the premium. Moreover, the new law allows from three to nine agency renewals aggregating 65 per cent. of one annual premium.

The above figures may not be technically accurate in every particular, but they are substantially correct. They clearly demonstrate that a uniform fee for a uniform service may be reasonably and justly placed at $\$ 5$.

Before closing, let me call attention to one illustration. The Equitable and the Mutual Benefit operate on the same per cent. basis, hence the mortality and reserve funds are the same (made so by law) for each company Each company arbitrarily fixes its own loading.

On a twenty-payment life policy at age of 35, the Equitable charges a premium of $\$ 38.34$, while the Mutual Benefit charges only $\$ 36.22$. On each $\$ 1,000$ of insurance, then, the Equitable collects from the policy holder $\$ 2.12$ for expenses more than does the Mutual Benefit on the same policy at the same age. But the Mutual Benefit pays a uniform medical fee of $\$ 5$, while the Equitable allows a fee of only $\$ 3$ on applications of $\$ 3,00$ । and less. Consequently, on each $\$ 1,000$ policy as illustrated, the Equitable has of the premium, after paying the medical fee, $\$ 4.12$ more than does the Mutual Benefit. While this difference alone is equal to 11 per cent. of the premium, the Mutual Benefit has an enviable reputation for paying large annual dividends to its policy holders.

a. Square Deal, M.D.

\section{Medical Fees in Country Practice.} Piimlipsburg, Kan., Oct. 15, 1906.

To the Editor:-I was very much interested in the article under the above caption which appeared in THE Journal, Oct. 6 , 1906, by Dr. W. O. Bridges.

Having been a country practitioner for almost 14 years, I can verify his statements regarding the small fees of country physicians. The charges in western Kansas do not differ materially from those in Nebraska or Iowa. Why the fees are so inadequate can be explained by cut prices and superficial medical training.

The question that interests most of us, however, is how to raise our fees sufficiently to inspire respect and confidence on the part of the laity. Dr. Bridges suggests that this can be attained by organization and a fee schedule. I do not believe that it can be accomplished in that way. In the first place all physicians do not have so keen a moral sense as they ought to have, and many will violate the fee agreement and make low fees. It is fact and not a theory that confronts us. In the second place, the same fee ought not to be charged by two physicians, one of whom has a very meager education, poor equipment and a "stand-pat" policy, while the other has up-to-date text-books, modern equipment, and makes a careful, conscientious study of every case entrusted to him. If these two physicians were called to treat a serious case in the country, would it be fair or just to hold them down to a charge of 50 cents a mile, because perchance the schedule said to do so? Is their skill the same? Would their advice be worth the same?

The fees charged should be based on merit. Every case should stand alone, and the charge should be made according to the seriousness of the condition, the responsibility assumed, the time consumed in its treatment, and the skill displayed. Why should a physician charge less for his arlvice, when human life is in the seale, than a lawyer for his, where the latter's advice involves a question of property worth from $\$ 300$ to $\$ 500$ ?

To illustrate: A farmer has trouble with a neighbor over the ownership of a calf or shoat. One or both consult a law. yer; he listens, collects a retainer fee of $\$ 10$ or $\$ 15$, and tells him he will take the case under advisement. The same farmer is taken ill, a physician is called and responds, plods through six or seven miles of mud, and the farmer makes a roar because the physician makes a charge of $\$ 5$. Why? Because the schedule says 50 cents a mile one way.

The lawyer has the farmer educated on the fee question; the physician has not. The condition will never become better until our patrons are taught that the charge is not for prescription, medicine or livery, but for knowledge and skill. Let us charge fair fees and, having charged, let us deliver the goods.

D. D. HaGgard, M.D.

Report of Relief Committee of Physicians of San Francisco. San Francisco, Oct. 25, 1906.

To the Editor:-I regret to notice that in its report, published in Trie Journal, Oct. 20, 1906, page 1311, the relief committee of physicians of San Francisco has omitted numer- 